\title{
Evaluation on the Urban Sustainable Development Level of Xicheng District in Beijing
}

\author{
Leigang Shi ${ }^{a}$, Cunjun $\mathrm{Li}^{\mathrm{b}}$, Haitang $\mathrm{Hu}^{\mathrm{c}}$, Xiang Sun ${ }^{\mathrm{d}}, \mathrm{Heju} \mathrm{Huai}^{\mathrm{e}}$ and Huarui $\mathrm{Wu}^{\mathrm{f}, \star}$ \\ Beijing Research Center of Intelligent Equipment in Agriculture, Beijing 100097,China \\ ashilg@nercita.org.cn, licj $@$ nercita.org.cn, chuht@ nercita.org.cn, ${ }^{\mathrm{d}}$ sunx@nercita.org.cn, \\ ehuaihj@nercita.org.cn, ${ }^{\mathrm{f}}$ wuhr@nercita.org.cn \\ * the corresponding author
}

\begin{abstract}
Keywords: urban sustainable development; entropy method; coordination index; sustainable development level
\end{abstract}

Abstract. Urban city plays important roles in the development of urban China. It is of highly strategic significance to evaluate the urban sustainable development level. In this paper, an assessment indicator system was designed composing of 4 first-level indicators and 20 second-level indicators. The entropy method was employed to calculate the development index of economic, social, resource and environmental subsystems, coordination index and sustainable development level of Xicheng District in Beijing during 2004-2013. An increase trend for sustainable development level was observed, from 0.30 in 2004 to 0.67 in 2013. The coordination index fluctuated with the best performance of 0.82 in 2007 and worst performance of 0.36 in 2004. The percentage of economic, social, resource and environmental subsystems was $20.03 \%, 40.53 \%, 18.13 \%$ and $21.31 \%$ respectively, and the sustainability index of social, economic and resource showed an increase trend during the past ten years.

\section{Introduction}

It is the premise for humanity's sustainable development that the urban economic, social, resource and environmental systems develop coordinately. Domestic and overseas scholars have conducted researches in areas of urban sustainable development theory, assessment indicators and policy recommendation ${ }^{[1-3]}$. Problems such as over-consumption of energy and environmental pollution are seriously threatening the sustainable development of Chinese cities ${ }^{[4]}$. China is positively exploring the path of sustainable development with Chinese characteristics in the guidance of sustainable development strategy. China National Sustainable Communities is a strategic mode to promote the coordinated regional social and economic development and also an effective way to realize the harmonious unity of humanity, resources and environment ${ }^{[5]}$. After development experiences for years, distinct development modes of sustainable communities have been formed exerting well radiation function ${ }^{[6]}$.

Xicheng District in Beijing is the first national sustainable community in China's central megacity area. It shoulders the task of leading the coordinate social and economic development by science and technology, promoting the common development of material and spiritual civilization, and constructing the sustainable urban communities. By evaluating the sustainable development level of economic, social, resource and environmental subsystems for Xicheng District, the government and stakeholder will be able to recognize the current situation of community development from statistic evidence. Other cities can also learn lessons from this case study for their sustainable community development.

\section{Method and Data}

Description of study areas. In July $19^{\text {th }}, 1995$, Xicheng District was issued as China National Sustainable Community. It is the first national sustainable community in China's central megacity 
area. Xicheng District is one of the central urban areas in Beijing(Figure 1), and representative China National Sustainable Community of urban type.

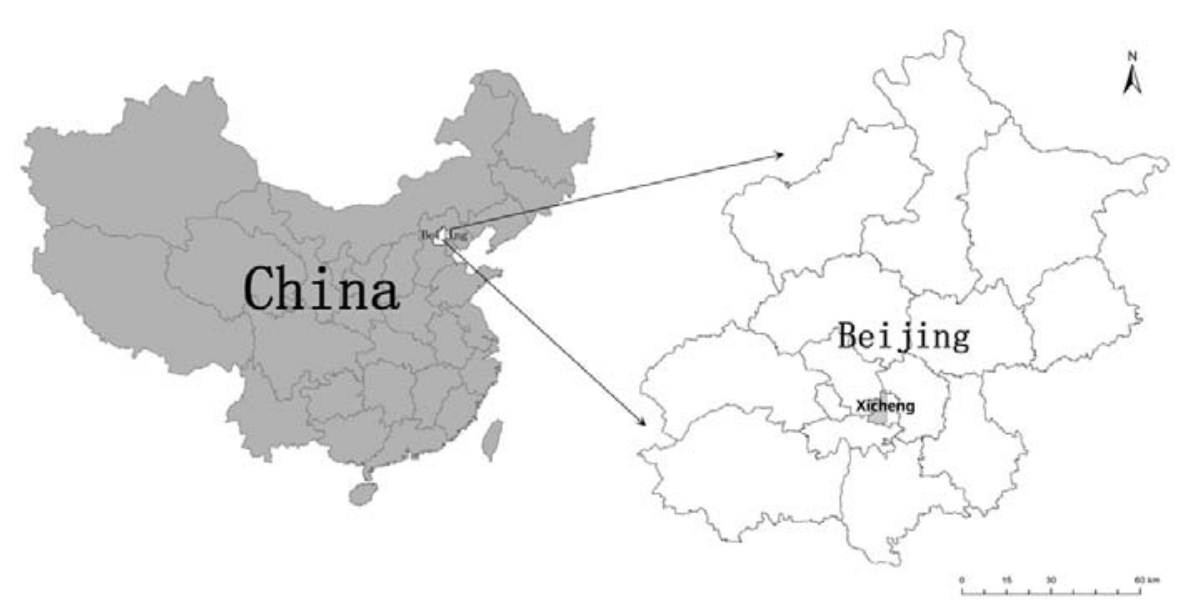

Figure 1. Location of Xicheng District in Beijing

Indicator selection and data source. The authors took into account the component of city system and regional sustainable development assessment theory, principle of completeness, comparability, and data accessibility, and employed the method of theory analysis and expert consultation. An assessment system for urban sustainable development level consisting of 20 indicators was built up from the view of economy, society, resources and environment (Table 1). Data were sourced from statistic year books of Xicheng District.

Table 1 Indicator system for assessing urban sustainable development

\begin{tabular}{|c|c|c|}
\hline First-level indicator & Second-level indicator & Weight \\
\hline \multirow{6}{*}{$\begin{array}{l}\text { Economic } \\
\text { subsystem }\end{array}$} & GDP per capita (yuan) & 0.0372 \\
\hline & Local financial revenue per capita (yuan) & 0.0509 \\
\hline & GDP growth rate per capita ( $\%)$ & 0.0232 \\
\hline & $\begin{array}{c}\text { Growth rate of local financial revenue per } \\
\text { capita (yuan) }\end{array}$ & 0.0221 \\
\hline & Percentage of service sector in total GDP $(\%)$ & 0.0364 \\
\hline & $\begin{array}{c}\text { Contribution rate of service sector in total } \\
\text { GDP increase }(\%)\end{array}$ & 0.0305 \\
\hline \multirow{8}{*}{$\begin{array}{l}\text { Social } \\
\text { subsystem }\end{array}$} & $\begin{array}{c}\text { Disposable income of urban residents } \\
\text { (yuan per capita) }\end{array}$ & 0.0477 \\
\hline & Proportion of planned birth (\%) & 0.0441 \\
\hline & $\begin{array}{c}\text { Number of professional doctors in every one } \\
\text { thousand pamement residents }\end{array}$ & 0.0551 \\
\hline & $\begin{array}{l}\text { Number of hospital beds in every one thousand } \\
\text { pamement residents }\end{array}$ & 0.0363 \\
\hline & Natural population growth rate $(\%)$ & 0.046 \\
\hline & $\begin{array}{c}\text { Number of library books per one hundred } \\
\text { residents }\end{array}$ & 0.0961 \\
\hline & Education expenditure per capita (yuan) & 0.0535 \\
\hline & Unemployment rate $(\%)$ & 0.0266 \\
\hline \multirow{3}{*}{$\begin{array}{l}\text { Resource } \\
\text { subsystem }\end{array}$} & Land use by urban residents per capita $\left(\mathrm{m}^{2}\right)$ & 0.0759 \\
\hline & $\begin{array}{c}\text { Energy consumption per unit GDP } \\
\text { (ton standard coal/10 thousand yuan) }\end{array}$ & 0.0602 \\
\hline & Water consumption per unit GDP $\left(\mathrm{m}^{3}\right)$ & 0.0452 \\
\hline \multirow{3}{*}{$\begin{array}{l}\text { Environmental } \\
\text { subsystem }\end{array}$} & Greening are per capita $\left(\mathrm{m}^{2}\right)$ & 0.1031 \\
\hline & Percentage of urban greening coverage $(\%)$ & 0.0433 \\
\hline & Environmental protection expenditure (\%) & 0.0668 \\
\hline
\end{tabular}


Assessment method. In this paper, entropy method was used to determine the sustainable development level of urban economic, social, resource and environmental subsystems and as a whole [7]

Since there existed difference in the dimension of distinct incomparable indicators of the assessment system of urban development, the indicators were made dimensionless at the first step. There were both positive and negative contributions to the system from the indicators. The equations below were employed to conduct data standardization. Each index $X_{i j}$ was converted into relevant dimensionless indicator $X_{i j}^{\prime}$.

1) Data standardization

$$
\begin{aligned}
& \mathrm{X}^{\prime}{ }_{i j}=\left[\mathrm{X}_{i j}-\min \left(X_{j}\right)\right] /\left[\max \left(X_{j}\right)-\min \left(X_{j}\right)\right] \quad\left(X_{i j} \text { as a positive indicator }\right) \\
& \mathrm{X}^{\prime}{ }_{i j}=\left[\max \left(\mathrm{X}_{j}\right)-X_{i j}\right] /\left[\max \left(\mathrm{X}_{j}\right)-\min \left(\mathrm{X}_{j}\right)\right] \quad\left(X_{i j} \text { as a negative indicator }\right)
\end{aligned}
$$

2) The weight of index $j$ for the year $i$

$$
Y_{i j}=\frac{X_{i j}^{\prime}}{\sum_{i=1}^{m} X_{i j}^{\prime}}
$$

3) Indicator information entropy

$$
e_{j}=-k \sum_{i=1}^{m}\left(Y_{i j}^{*} \ln Y_{i j}\right) \quad k=1 / \ln m
$$

4) Redundancy rate of information entropy

$$
d_{j}=1-e_{j}
$$

5) Indicator weight

$$
W_{j}=d_{j} / \sum_{j=1}^{n} d_{j}
$$

6) Assessment score of urban sustainability development

$$
\begin{aligned}
& \mathrm{SD}_{\mathrm{i}}=\sum_{j=1}^{p}\left(w_{j} \times X^{\prime{ }^{\prime}}{ }_{i j}\right) \\
& \mathrm{S}_{\mathrm{i}}=\sum_{j=1}^{n}\left(w_{j} \times X^{\prime \prime}{ }_{i j}\right)
\end{aligned}
$$

$X_{i j}$ represents the assessment result of city $i$ for indicator $\mathrm{j} . \mathrm{m}$ is the number of years, $\mathrm{n}$ is the value of indicator; $i=1,2, \ldots, m ; j=1,2, \ldots, n ; \max \left(\mathrm{X}_{\mathrm{j}}\right)$ and $\min \left(\mathrm{X}_{\mathrm{j}}\right)$ is the maximum value and minimum value of indicator $\mathrm{j}$ for all the studied years. $\mathrm{SD}_{\mathrm{i}}$ is the sustainability assessment score of year $\mathrm{i}$ subsystems (economic, social, resource and environmental subsystems). $X_{i j}{ }_{i j}$ is subsystem indicator, $\mathrm{w}_{\mathrm{j}}$ is the weight of relevant indicator, $p$ was the number of indicators, $S_{i}$ is the overall sustainability in year $i$.

Coordination index $U$ represents the coordination level of economic, social, resource and environmental development of Xicheng District. $\mathrm{S}_{\mathrm{ab}}$ is the coordination index between any two subsystmes. The bigger the value of $\mathrm{U}$, the more balanced between economic, social and environmental development will be, which indicates higher level of coordination development.

$$
\mathrm{U}=\frac{1}{6} \sum_{a=1}^{3} \sum_{b=a+1}^{4} S_{a b}=\frac{1}{6} \sum_{a=1}^{3} \sum_{b=a+1}^{4}\left(1-\frac{\left|S_{a}-S_{b}\right|}{\max \left(S_{a}, S_{b}\right)}\right) \quad(\mathrm{a}, \mathrm{b}=1,2,3,4 ; \mathrm{a} \neq \mathrm{b})
$$

\section{Results}

Weights of different indicators. Following the indicator weight determination method in the entropy method, the weights of 20 indicators were determined (Table 1). There were 9 indicators whose weight was bigger than 0.05 and 11 indicators whose weight smaller than 0.05 . The three indicators with highest weights were greening are per capita, number of library books per one hundred residents and land use by urban residents per capita. The three indicators with smallest weights were unemployment rate, GDP growth rate per capita and growth rate of local financial revenue per capita. The weights of the four subsystems were shown in the Figure 2. As can be seen 
from the figure below, the weight of social subsystem was biggest (about 2/5 of the total), followed by environmental and economic subsystems (about 1/5), and the environmental subsystem was smallest.

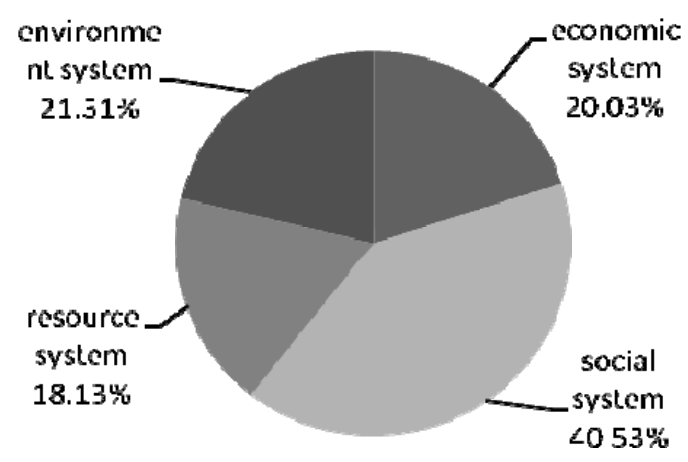

Figure 2 Weights of the four subsystems

Sustainable development of the subsystems. Following the equations for calculating sustainable development level of subsystems, the sustainable development levels of economic, social, resource and environmental subsystems of Xicheng District during the past ten years were calculated (Figure 3). In general, the sustainable development level of social subsystem showed obvious increase trend, with the annual average increase of 0.027 . The sustainable development levels of economic and resource subsystems also showed increase trend, with the annual average increase of 0.011 and 0.014 respectively. The variation of sustainable development level of environmental subsystem could be divided into two phases. During 2004-2008, the sustainable level was kept at around 0.14 and during 2009-2013 at around 0.05.

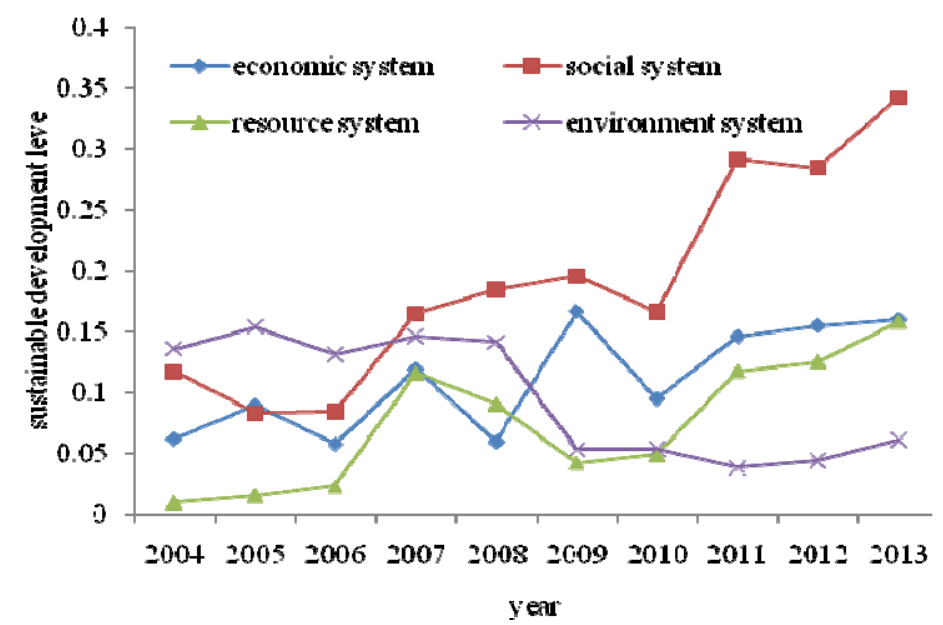

Figure 3 Trends of sustainable development levle of subsystems in 2004-2013

The urban sustainable development level and coodination index of Xicheng District during 2004-2013 were calculated (Figure 4). In general, the urban sustainable development level of Xicheng District showed increase trend, from 0.30 in 2004 to 0.67 in 2013. During 2004-2013, the coordination index of economic, social, resource and environmental subsystems flucuated. It peaked at 0.8 in 2007, kept at around 0.41 in 2004-2006 and fluctuated around 0.45 in 2008-2013. 


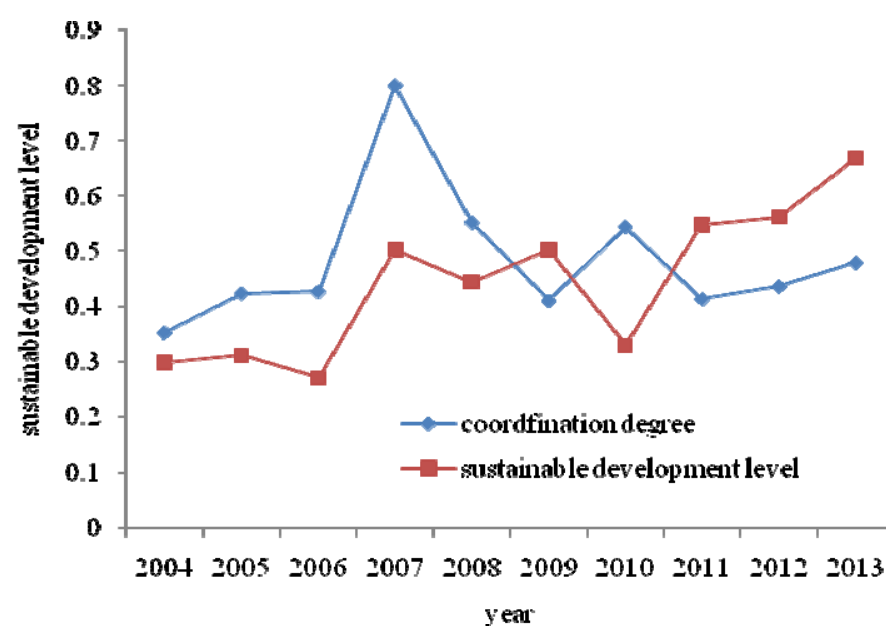

Figure 4 Sustainable development level and coordination index of Xicheng District during 2004-2013

\section{Conclusion}

In this paper, the urban sustainable development level of Xicheng District in Beijing during 2004-2013 was assessed, with a remarkable increase trend observed. The sustainable development level in the year 2013 was 2.23 times that of 2004 . There existed a substantial difference between the sustainable index of economic, social, resource and environmental subsystems. In the next step, the authors will try to explore the coordination mechanism between economic, social, resource and environmental subsystems and interactions between main influential factors. Common problems will be summarized to provide reference for other cities.

\section{Acknowledgements}

This work was financially supported by National Key Technology Support Program(2013BAJ04B04).

\section{References}

[1] J. Rinne, J. Lyytimäki, P. Kautto. From sustainability to well-being: lessons learned from the use of sustainable development indicators at national and EU level. Ecological Indicators.Vol.35(2013),35, 35-42

[2] R.K. Singh, H.R. Murty, S.K. Gupta, et al. An overview of sustainability assessment methodologies. Ecological Indicators. Vol.15(2012), p. 281-299

[3] C.Y. Lin. The evolution of Taipei's music industry: Cluster and network dynamics in the innovation practices of the music industry. Urban Studies, Vol.51(2014), p. 335-354

[4] K.M. Zhang, Z.G. Wen. Review and challenges of policies of environmental protection and sustainable development in China. Environ. Manage. Vol.88(2008), p.1249-1261

[5] N. Yao, M. Song, X.M. Liu. Situation analysis of the implementation and effectiveness of science and technology projects in China National Sustainable Communities. China Population, Resources and Environment, Vol.25(2015), p. 158-161

[6] X. Chen, X. Liu, D. Hu. Assessment of sustainable development: a case study of Wuhan as a pilot city in China. Ecological Indicators. Vol.50(2015), p. 206-214 
[7] J. Li, M.M. Cao. Comparative study of development level on China national sustainable communities. Bulletion of Soil and Water Conservation. Vol. 31(2011), p. 160-164 (in Chinese with English abstract) 